\title{
Development of radiation education in schools after the Fukushima Daiichi nuclear power plant accident - a study from the perspectives of regionality, multidisciplinarity and continuity
}

\author{
Yujiro Kuroda ${ }^{1,2, *}$, Masaharu Tsubokura ${ }^{1}$, Kiyoshi Sasaki ${ }^{2}$, Takashi Hara ${ }^{3}$, Atsushi Chiba ${ }^{3}$, \\ Keishin Mashiko ${ }^{4}$ and Thierry Schneider ${ }^{5}$ \\ ${ }^{1}$ Fukushima Medical University, Fukushima, Japan. \\ 2 Fukushima Prefectural Centre for Environmental Creation, Fukushima, Japan. \\ 3 Soma Municipal Sakuragaoka Elementary School, Fukushima, Japan. \\ ${ }^{4}$ Sakuragaoka Elementary School, Sakuragaoka, Japan. \\ 5 Nuclear Protection Evaluation Center (CEPN), Fontenay-aux-Roses, France.
}

Received: 24 September 2020 / Accepted: 11 November 2020

\begin{abstract}
This study was designed to examine how teachers in Fukushima Prefecture have shaped radiation education and gained consensus on radiation-related issues since the Fukushima Daiichi nuclear power plant accident. We interviewed teachers and external experts who have been conducting radiation education since the nuclear accident, ascertaining their focus in introducing and implementing radiation education and the lessons they have learned. We then qualitatively analyzed the results. There was no practical radiation course of study (Shido Yoryo) to follow immediately after the disaster, so teachers individually devised curricula according to the developmental stages of their students. Their aims were to (1) tailor lesson structure to the students' anxieties and distress, (2) promote students' activities through knowledge and linkage to their daily lives via radiation measurements and disaster site visits, and (3) enable the students to self-educate and to take informed decision. These objectives required the implementation of continuous, multidisciplinary radiation education to enable the students to understand the impacts of the nuclear accident and enhance the resilience of children growing up in Fukushima, allowing them to overpass the rumor and stigma and to adopt adequate protective measures to face the remaining radiation in their environment. As nearly 10 years has passed since the accident, radiation education at schools has reached a turning point. While social interest in radiation education is waning, it is hard to say that adequate radiation knowledge has taken root among students, and therefore it is necessary to consider how radiation education should be delivered in the future. Such curricula based on the experiences of Fukushima Prefecture should be shared internationally in preparation for potential future accidents.
\end{abstract}

Keywords: radiation education / co-expertise process / Fukushima / post-accident / self-stigma

\section{Background}

The Great East Japan Earthquake of 11 March 2011 caused the Fukushima Daiichi Nuclear Power Plant (NPP) to release radioactive materials, which widely contaminated Fukushima Prefecture (Yoshida and Kanda, 2012). The Prefecture started decontamination activities from fiscal year (FY) 2012 and has been monitoring radiation at various locations and continuously providing accurate information based on the results (risk communication) to the residents (Gilmour et al., 2016;

*Corresponding author: kuroday@fmu.ac.jp
Murakami et al., 2017). However, because radiation is invisible and impalpable, it is barely comprehensible to the general public, and a concern persists among the public that radiation exposure may cause physical damage in the future (Suzuki et al., 2015). In addition, even if a person was not exposed to radiation but their parents or grandparents had been, the person may become anxious about future disorders (genetic effects). So the one-way supply of information from experts to people is limited in its ability to reassure the public (the information deficit model approach) (Kuroda et al., 2018). Because these issues are common to both adults and children (Kuroda, 2017), it is very important to provide radiation education in schools. 
Radiation education had been barely taught in high schools for about 30 years until March 2008, when a new course of study (Shido Yoryo) for junior high school science was designed (Yoshida, 2018). In March 2011, the very month when a new course was in preparation, the accident at the Fukushima Daiichi NPP occurred. The Ministry of Education, Culture, Sports, Science and Technology therefore revised the Course of Study, and from FY 2012, science education for third grade junior high school students (between the ages of 14 and 15) incorporated radiation topics in science, technology and human science classes. However, only physics teachers had received adequate education in radiation. To know whether it is possible to provide radiation education based on supplementary books in primary and secondary education, a questionnaire surveyed junior high school teachers, and found that most lacked the relevant knowledge (Bekki, 2013; Hosaka, 2012). In addition, the contents of the supplementary books were so difficult to understand that some municipalities prepared new books (Yoshida, 2018).

Against such a background, how teachers in Fukushima Prefecture shaped radiation education and reached consensus on radiation-related issues after the disaster is expected to be useful in shaping long-term radiation education. However, reports issued so far are no more than analyses of existing curricula rather than development of new curricula (Okada, 2014; Yamaguchi, 2019), or were intended for emergency response education in universities or for nurses (Konishi et al., 2016; Nukui et al., 2018; Ohno and Kaori, 2011; Yasui et al., 2017). Many teachers took steps to craft new radiation education courses that met the specific needs of their students. Here we report a qualitative analysis of four cases of pioneering, teacher-initiated courses that can inform future radiation education programs for students at different levels.

\section{Methods}

The first step was the identification of teachers and experts who provide radiation education at schools in Fukushima Prefecture, considering:

- teachers at schools that continuously taught radiation education after the accident;

- teachers and experts who taught multidisciplinary radiation education;

- outside experts who supported radiation education.

We selected primary, junior high and senior high school teachers and academic experts by using the methodology of snowball sampling (Goodman, 1961).

We surveyed:

- post-earthquake disaster responses related to radiation at schools (students and teachers);

- issues found in providing radiation education (considerations before starting, difficulties in introduction, and responses of students);

- experiences in radiation education (transition, development, difficulties and how they were handled, and lessons learned by teachers);

- achievements (e.g., Courses of Study for radiation education as deliverables, spillover effect on other teachers, networking);

- types of education necessary in the long-term.
Each respondent submitted examples and documents regarding the above items. Then one of us (Y.K.) conducted supplementary interviews with each respondent. Y.K. then performed qualitative content analyses (Mayring, 2000) by using MAXQDA to facilitate the analysis. The respondents checked the results of the analyses and added their opinions.

\section{Results}

After our initial survey, we interviewed four individuals (teachers or experts) in depth and present the qualitative analysis below. The major findings are summarized in Table 1.

\subsection{Regional characteristics of radiation education in primary schools after the accident}

Soma Municipal Sakuraoka Primary School, about $40 \mathrm{~km}$ north of the Fukushima Daiichi NPP, has the highest number of students in Soma City. After the disaster, about 70 children (out of $479 ; 14.6 \%$ ) were transferred to other schools for various reasons, but another 30 joined the school from Minamisoma City and Namie Town, which are closer to the NPP. A fifthgrade class taught by K.M. ended up with 23 students. With the hope of fostering their consciousness and pride in supporting and being engaged with one another in Soma City and more broadly in Fukushima, K.M. focused on:

- teaching accurate knowledge of radiation;

- deepening the recognition of the current situation in Soma City;

- teaching effective ways of understanding and thinking in regard to safety and security;

- coexistence with community.

K.M. felt that opportunities for obtaining accurate information on Soma City were limited, even within the city. For example, news of three harvests of octopus in Soma (which is important for local community) was available only through the media. K.M. thought it important to directly attend to information on crucial resources such as drinking water, rice, the staple food; and foods harvested from the sea off Soma. He felt that it was important not to be afraid of everything, but to judge appropriately in order to continue living in Soma. Because the final judgment of safety and security depends on the individual, obtaining accurate information and using it effectively are necessary. Thus, K.M. titled his radiation education material in FY 2012 "The Current Situation of Our Hometown Soma". He thought that deepening views and ways of thinking about the "safety and security" of food through the accurate recognition of the situation in Soma and accurate knowledge would help to cope appropriately, even if exposed to uncertain information and hoped to foster affection for Soma among his students. K.M. provided his students with opportunities to learn from visiting speakers, to visit the fisheries association to observe the instruments used for measuring radiation, to visit orchards to learn the situation on farms, and to learn about the dynamics of cesium such as adsorption in water and soil at a water service association and the JA (Japan Agricultural Cooperatives) Soma. 
Table 1. Characteristics of the interviewees' basic situation and efforts.

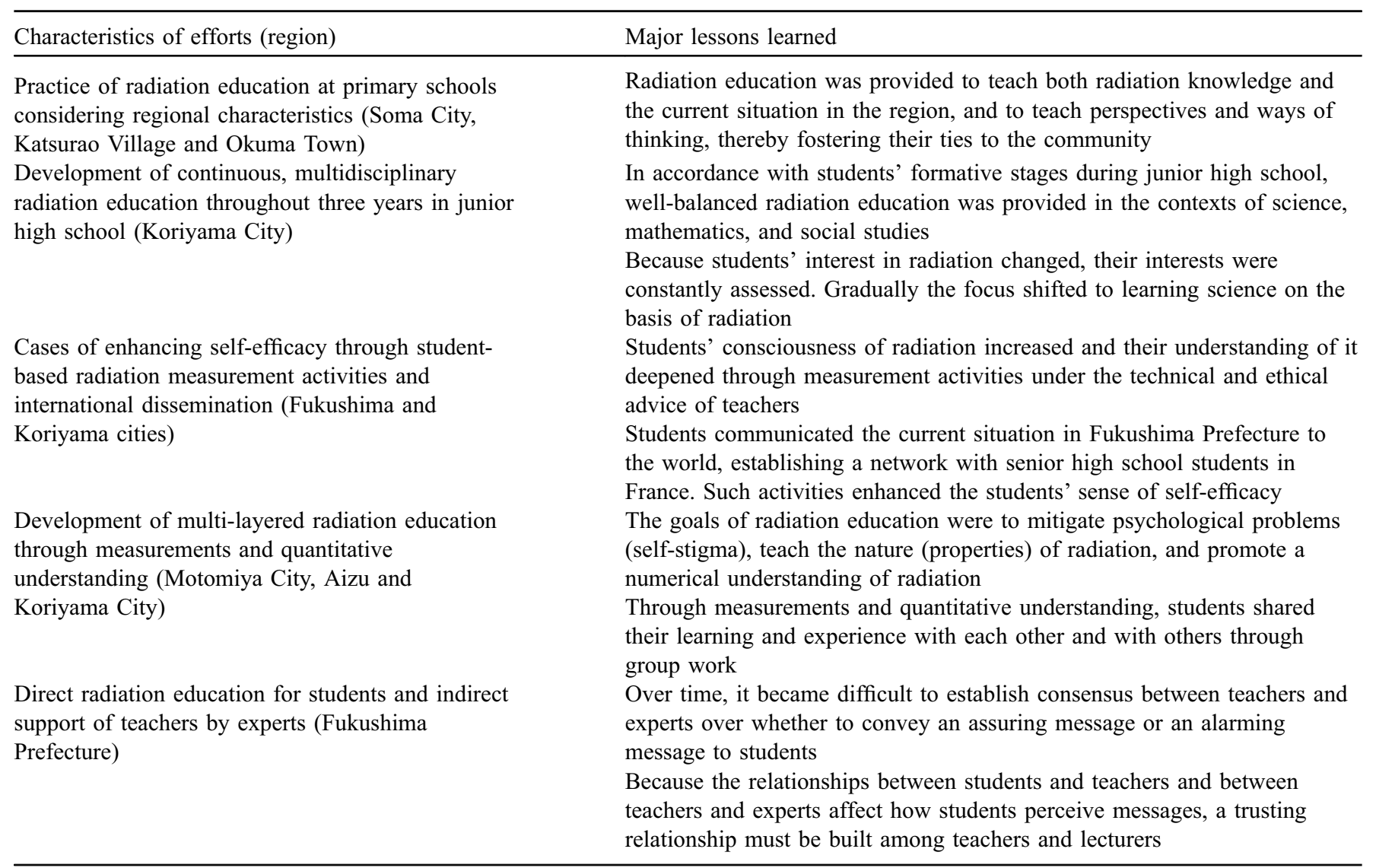

\subsection{Development of continuous multidisciplinary radiation education throughout three years in junior high school}

At the time of the disaster, the students and teachers of Koriyama Municipal Meiken Junior High School in Koriyama City felt scared. Koriyama City, in the prefectural central district, is a region with a relatively high radiation level at the time of the disaster. Even by late March, real-time air dose rates were not accurately reported, so each municipality started its own radiation protection activities, such as dose measurements and decontamination. However, there were no teachers with experience in radiation education, and the education board and schools held no radiation measuring instruments. Amid such a situation, K.S. asked himself, "What should I do now?" and concluded, "Develop a guidance plan for radiation education and start radiation education classes as soon as possible". K.S. started radiation education in September 2011.

K.S. first set four "abilities to be acquired by students" that would allow students to overcome difficulties as residents of Fukushima Prefecture by thinking and acting both individually and jointly:

- to accurately measure radiation levels';

- to analyze data and recognize changes in radiation levels;

- to select information based on scientific evidence, thereby making an informed judgment;
- to discuss radiation levels on the basis of scientific evidence and understand other opinions with a view to reducing radiation exposure.

K.S. also developed a "guidance plan for radiation education through junior high school science curricula" (Tab. 2).

In the first year of radiation education, the students were given opportunities for contemplation and problem solving, such as being asked to suggest why air dose rates at some locations in the school yard where surface soils were buried were high, thereby clarifying their thinking processes and fostering their ability for scientific thinking, judgment and expression. Themes were set through daily observations of the students and questionnaires to incorporate what they wanted to learn in the classes, thereby enhancing their motivation for learning. In "team teaching", a nursing teacher helped the students recognize the importance of enhancing one's immunity (through a balanced diet, good sleep and rest, and moderate exercise), in addition to the importance of scientific abilities. In the second year, under the theme of "radiation education to foster the ability for scientific inquiry", classes previously called "learning the knowledge of radiation" were renamed "learning science on the basis of radiation". The third year emphasized "people-to-people connections", because even if students learn the skills for scientific inquiry, it does not mean that they can understand the realities of residents 
Table 2. Key points in the guidance plan for radiation education in junior high school.

(1) Radiation education must be introduced in the first year before "nature and humans" can be taught in the third year

(2) Students should learn to perform scientific analyses with data on daily radiation doses

(3) Students should go beyond the mere presentation of information by conducting experiments, measuring levels, making models, analyzing nuclear accidents, etc.

(4) Radiation education must be linked to comprehensive learning of the effects of radiation on human health, radiation protection measures, etc.

(5) Students should take up the subject in the context of the history of science, which should include an introduction to the contributions of various scientists to radiation education

(6) Radiation teaching should consist of three pillars: "knowledge", "observation/experiments" and "facts"

experiencing radiation problems in Fukushima Prefecture. The school invited the workers decommissioning the Fukushima Daiichi NPP and staff of the Tokyo Electric Power Company to the school to directly explain their work.

\subsection{Enhancing self-efficacy through student-based radiation measurement activities and international dissemination}

Fukushima High School in Fukushima City (prefectural north region) is designated a "super science high school" (focused on technology, science and mathematics) and cooperates with universities and research institutions. Although two of its four buildings were destroyed by the earthquake, the gymnasium and audiovisual room were renovated as accommodation for 568 evacuees from Namie and Okuma towns by 10 April 2011. Although classes restarted in mid-April, outdoor activities remained a concern. Because the radiation level in the schoolyard satisfied the standard for outdoor activities, activities resumed, but the swimming pool was closed. As fears of the radiation spread among the students, their families and teachers, physics teachers, in anticipation of the full-scale restart of the school, carried out a radiation survey of the school and published the results on the school website.

The students are supposed to start research projects from the second grade, but the facilities were closed. However, T.H. was able to borrow radiation-measuring instruments and invited students to use them. First, the students learned how to use a dosimeter. They tested whether the schoolyard satisfied the standard for outdoor activities and checked for the presence of hot spots to raise their awareness of potential problems. During the holidays in May, they carried out a radiation survey in the school, prepared a radiation map, and published it on the school's website (Fig. 1). They next measured the radiation levels in their neighborhoods and along school routes. The various types of dosimeters available give different measurements, so the students compared their results. Radiation levels presented daily on TV were sometimes higher in Fukushima City than in Soso District, which is nearer to the NPP. The students wanted to understand why, so they conducted a project.

High schools' Super Science clubs reported their results at nationwide meetings in FYs 2011 and 2012 and again at the International Commission on Radiological Protection (ICRP) Dialogue Seminar in Fukushima City in May 2015. One of us (T.S.) met the Super Science clubs during the seminar and proposed a collaboration between the clubs and high schools in
France. The first meeting (on the Web) was attended by 52 students from two high schools in France (BoulogneBillancourt and Poitiers) and 33 students from three high schools in Japan (Fukushima, Fukushima Minami, and Adachi) who discussed radiation and introduced their efforts. Later, with the support of Prof. Ryugo Hayano, professor of physics at the University of Tokyo, high schools students from 12 schools in Japan and 12 regions in three other countries (216 students in total from Belarus, France, and Poland) measured external dose in June 2014 (Japan) and autumn 2014 (others). The students, with the help of the professors, analyzed the results, identifying the variations and putting them into perspective. The results were published in an international journal (Adachi et al., 2016), which greatly raised the selfconfidence of the students in Fukushima Prefecture. Since 2015, the students have met with other students from Japan and overseas in an international radiation protection network that provides experience-based learning on radiation and reconstruction matters, addressing both the evolution of the radiological situation as well as the socio-economic situation in the Fukushima Prefecture.

\subsection{Development of multi-layered radiation education through measurements and quantitative understanding}

Students at Fukushima Prefectural Motomiya High School in Motomiya City (prefectural central district) were fearful of radiation in the wake of the disaster, as some surrounding areas were contaminated at relatively high levels. A boy in third grade asked a teacher who was newly employed in April 2011, immediately after the disaster, "We will not be able to have normal children, will we?" A.C. was at a loss as to how to answer. Most of the students harbored anxieties but were unable to express them. Many felt internalized (self-)stigma (a prejudice or discriminatory attitude toward oneself). A.C. felt that to remove such selfstigma, it was important for students to grasp the nature of radiation and to promote their numerical understanding of it. However, objective data were scarce in the aftermath of the accident, and the contents of novice teachers' training were not adequate for practical use. The school neither had a network to secure outside cooperation for radiation education in the school, nor was much engaged in radiation education inside it, so it was unable to obtain effective advice.

Therefore, A.C. implemented radiation education while feeling his way, such as running experiments during science 


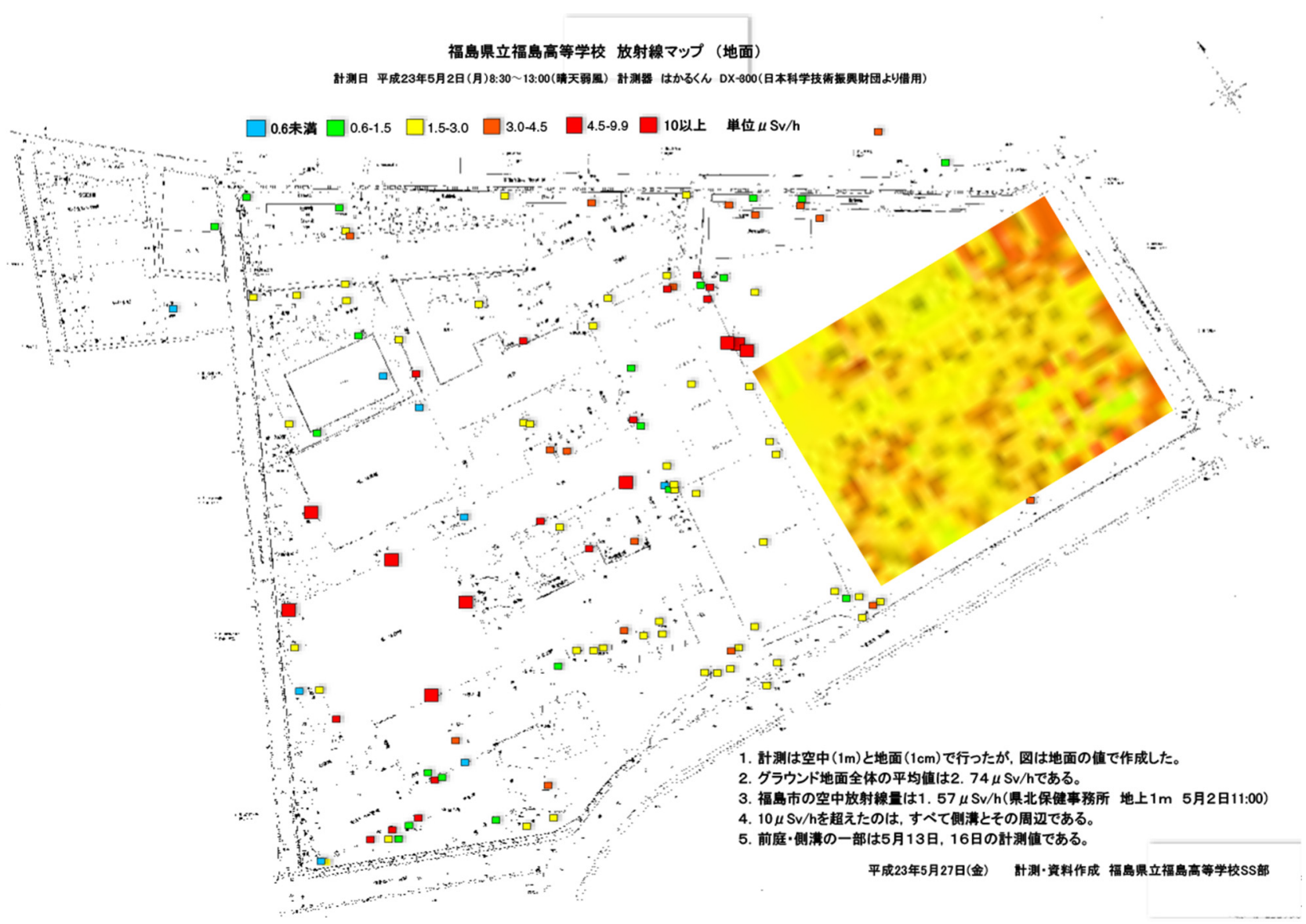

Fig. 1. A radiation map around the school created by an SSH student. This map was created by Fukushima High School students who measured air dose rates around their school. It is explained in Japanese that the measurement was made on May 2, 2011 and the map was made on the 27th. The colors of the map are divided into blue less than $0.6 \mu \mathrm{Sv} / \mathrm{h}$, green $0.6-1.5 \mu \mathrm{Sv} / \mathrm{h}$, orange $1.5-3.0 \mu \mathrm{Sv} / \mathrm{h}$, red $4.5-9.9 \mu \mathrm{Sv} / \mathrm{h}$ and more. It was also noted that all areas exceeding $10 \mu \mathrm{Sv} / \mathrm{h}$ were in and around gutters.

classes (radiation attenuation in proportion to distance, the measurement of radioactive materials present in daily life, shielding experiments, etc.). The initial purpose was to allay students' self-stigma, because it was not possible to show that radiation cannot affect their future children. Experiencing much difficulty, A.C. decided to teach only objective facts, for example by saying, "This value has been found to result in a phenomenon such as..." The teacher's goal was to "promote numerical understanding based on the understanding of the nature (properties) of radiation". He revised the curriculum as many as 30 times, finally deciding on the following themes:

- the basics of radiation;

- radiation experiments;

- the current situation in Fukushima Prefecture (results of food inspections, air dose rate measurements, and measurements using whole-body counters);

- tasks for the Prefecture (current situation of the Fukushima Daiichi NPP and damage to its reputation, and sociological analyses);

- efforts taken by the Prefecture (situation after the evacuation order was lifted and post-earthquake disaster efforts).
This curriculum was based on measurements and quantitative understanding and was characterized by the sharing of results through group work. A revised supplementary booklet was compiled, the experiences of veteran teachers and students' opinions and assessments of the classes were gathered, and the teacher's approach was validated.

\subsection{Direct radiation education for students and indirect support of teachers by experts}

This section presents examples of radiation education support provided by outside experts. Since immediately after the disaster, one of us (M.T.) has provided 1- to 2-hour classes on radiation and health in response to requests from teachers and administrative bodies. What surprised M.T. was that school teachers themselves were initially very skeptical of the contents of radiation education. Normally, radiation education classes should be presented by both a lecturer and a teacher. Initially, however, the lecturer addressed both teachers and students (which prevented follow-ups questions for promoting students' understanding). As teachers themselves gradually 
gained radiation knowledge, the situation changed, and the teachers began to select lecturers. In this way, a situation emerged in which teachers invited lecturers they thought favorable, or (because certain hours of radiation education became compulsory) teachers had to invite lecturers even when they did not think the latter favorable. In the longer term, the number of teachers setting long-term objectives of radiation education decreased. At some schools, a lecturer in charge of radiation education was assigned to a novice teacher. Other schools had teachers too emotionally involved with the radiation education who thus had an ideologically biased tendency. This situation made it difficult to hold effective workshops.

M.T. wrote: "Because students are strongly influenced by teachers, ..., how ardently a teacher introduces a lecturer to the students at the start of a class ... determines [how] seriously [students] listen to the lesson" (Tsubokura et al., 2018). Therefore, when a teacher and a lecturer have a favorable relationship, the students perceive a favorable atmosphere. Contrariwise, for example, when a teacher perceives the current situation as unsafe but a lecturer feels it safe and lectures accordingly, students are unlikely to accept the lecturer's views. The degree of students' understanding substantially differed depending also on where a class was held (such as in a gymnasium or in a small group).

One decision to make was under what subject radiation education should be provided to students. For example, it may partially fall under various categories, such as risk education, health education, physics, general science, and sociology. The contents and key points of a class depend on the background and goals of the teacher, and on the message that the students are expected to learn. For example, in traffic safety education, students are taught to be careful even when the signal is green, because a driver might not stop. However, from the point of view of radiation protection, overdoing preventive measures sometimes might not be the optimal protective measures. While being careful about radiation could be one of the main purposes of radiation education, to provide a sense of safety, maintain self-respect, enhance self-confidence, or understand one's own condition (such as "we are not suffering from internal exposure") could also be also important for radiation education. M.T. believes that self-stigma or bullying must not undermine the futures and potentials of children, and that protecting them from such harms should be a major purpose of radiation education, when the levels of radiation exposure among residents are low enough for possible future health effects to statistically indiscernible, such as after the Fukushima accident due to the protective measures adopted following the accident and the low residual level of contamination for most of the living areas. In such a context, M.T. holds the following two points as the basis of the content taught in class:

- radiation is present in nature, and nobody is exempt from exposure;

- its effect on health is proportional to exposure.

M.T. holds these to be fundamental lessons. On the other hand, some people think that it is more important to be focused on daily living and to know which foodstuffs may have been contaminated and which locations may be hot spots. In reality, the balance between these ways of thinking has not previously been considered, and their relationship with long-term objectives has not been planned in most cases.

\section{Discussion}

This study qualitatively analyzed four cases ranging from primary to high schools in Fukushima Prefecture to clarify how teachers shaped radiation education after the disaster. No radiation-related courses of study existed immediately after the disaster, so each teacher developed curricula according to the formative stages of their students. The curricula were characterized by:

- tailoring lesson structure to students' anxieties and distress; - promoting students' activities through knowledge and linkage to their daily lives via radiation measurements and disaster site visits;

- setting a goal of enabling students to self-educate, mitigate self-stigma and allow them to take informed decision about their protection.

The first key point is that since the Fukushima accident, concerns about long-term psychological impacts, discrimination, and prejudice (including self-stigma) remain (Maeda and Oe, 2017; Oe et al., 2016). This suggests that children and students who were living in Fukushima Prefecture at the time of the disaster may be prone to discrimination and prejudice. A health survey regarding radiation risk that was conducted throughout the prefecture found that few adults worried about acute exposure, but nearly $40 \%$ of them still worried about the effects on the next generation (Oe et al., 2017). Such anxiety about radiation impacts on the next generation tends to lead to self-stigma, such as worrying about whether one can marry and have children (Bromet, 2014; Ohto et al., 2017). Research targeting primary and junior high school students in Fukushima suggested that the ratio of children deemed to require professional support has been decreasing since the disaster but remains higher than the national level (Mashiko et al., 2017). Our research found several cases in which the class structure was tailored to the anxiety and distress of the students, and it was clear that the goal of radiation education was to mitigate self-stigma and promote informed citizen with regard to radiological protection issues. A survey conducted at Asaka High School showed that the percentage of students who answered as "having radiation knowledge and able to explain it to others" rose from $2 \%$ before the classes started to $46 \%$ after the classes ("having a moderate knowledge of radiation": $42 \%$ before and $98 \%$ after) (Chiba, 2019). Even those who may experience stigma outside Fukushima Prefecture can prevent it if they are able to explain the actual situation of the prefecture and radiation in their own words.

The second key point is that radiation education should be implemented not only in science classes, but also in other classes such as mathematics, domestic science, ethics, social studies, and health. This would ensure that well balanced, continuous, multidisciplinary radiation education covers the complex effects of the NPP accident in a multifaceted way and enhances the resilience of children growing up in Fukushima, even in the face of reputational damage and self-stigma, and 
favour the identification of the challenging issues associated with the presence of radioactivity in the environment. In the aftermath of the accident, radiation-related educational resources were in short supply, but now that the experiments of teachers have been consolidated, the prefectural education board and the local boards of education have issued radiation education guidelines, and adequate radiation teaching materials have been developed. It is necessary to incorporate the aspect of "people-topeople connections" into future radiation education in Fukushima Prefecture and to link it with other fields such as social studies and ethics. Given that still there are evacuated students living outside the prefecture and that prejudices and rumors harbored by people there persist, the issue of nationwide radiation education should also be reviewed.

Lastly, each teacher developed curricula according to the formative stages of students. Compulsory radiation education at primary and junior high schools is characterized by a focus on people, such as visiting and hearing from decommissioning workers, in addition to the science. Because senior high school students have the necessary number skills, their radiation education is characterized by being able to judge the meaning of numbers they encounter daily, learning the effects on the body and genes in a numerical sense, and incorporating scientific knowledge obtained from Hiroshima and Nagasaki. As shown by the example of Fukushima High School, while the students experienced a loss of trust immediately after the accident, they became motivated to investigate the real situation through radiation measurements rather than passively accepting media information, which resulted in the incorporation of "measurements" into classes. Efforts to incorporate the learning of "health effects" and the "actual situations of disaster-stricken areas" into the curricula, as well as tailoring the courses to the students' anxieties and distress levels, have brought about major lessons. The result is that whereas the courses of study in place before the accident were practically unusable, the new curriculum based on Fukushima's experiences is suitable to be shared internationally to prepare students for future accidents. In addition, for the students, listening to testimonies from people (farmers, fishermen, health professionals...) facing the consequences of the accident has proved to be fruitful to better understand what is at stake in terms of radiation and socio-economic issues even 10 years after the accident.

However, waning interest in radiation education and ideological fixation (bipolarization) at schools remain problems (Orita et al., 2015). Bertho et al. (2019) conducted a radiation education project in the post-Chernobyl Komarin village of Belarus, showing high interest in the results among students. The two high schools in Fukushima, which are the targets of this study, also have radiation protection activities led by student clubs, and the necessity of fostering a radiation protection culture by these young generations is similar in Fukushima and Belarus, and is considered important for longterm measures. One thing to add, however, is that the interest in radiation education among students as a whole is declining, and there is a growing polarization between those who are highly interested in radiation and those who are not. The sustainability of radiation education has been discussed in both Fukushima and Belarus, and in response to this, a special facility for radiation education was established in Miharu-machi in Fukushima in 2016, creating a system for schools in Fukushima Prefecture to receive systematic radiation education. About $60 \%$ of elementary schools in Fukushima Prefecture use the system, suggesting its effectiveness. In addition, it has been suggested that providing information between students from high-interest groups, such as student clubs, to low-interest groups is more effective than providing information uniformly. Continuing efforts to provide information from students to students is also necessary for sustainability. The feedback following the Chernobyl accident shows the importance of organizing the networking of school initiatives, allowing the students to share their experience and initiate new projects (Bertho et al., 2019). Keeping the memory and transmitting the radiological protection culture to the young generation are crucial for maintaining the long-term vigilance on radiation protection issues. In the field of health communications, health information provided to the public should include risks and benefits (Goto et al., 2018). The Clear Communication Index developed by the US Centers for Disease Control and Prevention recommends that risk-related health information should explain:

- the nature of risks;

- the benefits and risks of a recommended action;

- the meaning of a numerical probability in verbal or visual terms (DeWalt et al., 2011).

The main purpose of disseminating health information is to support the general decision-making process and is not specific to radiation education. When targeted at students, such information should be age specific.

The second key point is radiation education for students who evacuated from the prefecture. As of April 2012, 30109 evacuees younger than 18 were originally recorded in the prefecture, of whom 17895 had evacuated outside the prefecture. As of April 2018, the number was 17487 in all areas, of which 7422 were evacuated within the Prefecture and 7575 outside the prefecture (2490 in their original location within Fukushima), but many students still remained evacuated outside the Prefecture. Some survey results indicated that voluntary evacuees are more affected than those remain in the prefecture by poor mental health (Tsujiuchi et al., 2016). Although Fukushima Prefecture is blessed with a unique opportunity for radiation education, other regions are not necessarily so, and therefore many students displaced by the disaster may still suffer from self-stigma.

Despite these limitations, the results show the experiences of teachers who have been able to provide radiation education since the accident. The three major lessons derived can bring about useful knowledge in terms of both preparation for a future nuclear disaster and fostering science literacy in schools.

\section{References}

Adachi $\mathrm{N}$, et al. 2016. Measurement and comparison of individual external doses of high-school students living in Japan, France, Poland and Belarus-the 'D-shuttle' project. J. Radiol. Prot. 36(1): 49-66. doi:10.1088/0952-4746/36/1/49.

Bekki M., Morikawa N, Tsukada S, Akishige Y. 2013. Investigation of a teacher's consciousness to radiation education and a teaching material. Bull. Cent. Support. Educ. Shimane Univ. 12: 43-51.

Bertho JM, Maître M, Croüail P, Naito W, Shkliarava N, Mostovenko A, Jones K, Cornu MS (2019). Assessment of population radiation exposure at the edge of the exclusion zone 32 years after the 
Chernobyl accident: methods and preliminary results. Radioprotection 54(4): 247-257.

Bromet EJ. 2014. Emotional consequences of nuclear power plant disasters. Health Phys. 106(2): 206-210. https://doi.org/10.1097/ HP.0000000000000012.

Chiba A. 2019. Classes relating to Fukushima reconstruction and radiation physics education.J. Phys. Educ. Soc. Jpn. 67(4): 235-240.

DeWalt DA, Broucksou KA, Hawk V, Brach C, Hink A, Rudd R, Callahan L. 2011. Developing and testing the health literacy universal precautions toolkit. Nurs. Outlook. 59(2): 85-94. https:// doi.org/10.1016/j.outlook.2010.12.002.

Gilmour S, Miyagawa S, Kasuga F, Shibuya K. 2016. Current measures on radioactive contamination in Japan: A policy situation analysis. PLoS One 11(3): e0152040. https://doi.org/ 10.1371/journal.pone.0152040.

Goto A, Lai AY, Kumagai A, Koizumi S, Yoshida K, Yamawaki K, Rudd RE. 2018. Collaborative processes of developing a health literacy toolkit: a case from Fukushima after the nuclear accident. J. Health Commun. 23(2): 200-206. https://doi.org/10.1080/ 10810730.2018 .1423650 .

Goodman L. 1961 Snowball sampling. Ann. Math. Stat. 32(1): 148-170.

Hosaka M, Fujita K. 2012. The current situation and issues of radiation learning in junior high school science classes. An educational research report by the Faculty of Education and Human Studies, Akita University. 34: 25-34.

Konishi E, Nagai T, Kobayashi M, Mitsumori Y, Ono W, Asahara K, Porter SE. 2016. Post-Fukushima radiation education for public health nursing students: a case study. Int. Nurs. Rev. 63(2): 292299. https://doi.org/10.1111/inr.12244.

Kuroda Y. 2017. Public health activities contributing to recovery of life after nuclear emergency: lessons from working with Iitate people. J. Public Heal. Pract. 81: 328-334.

Kuroda Y, Iwasa H, Orui M, Moriyama N, Nakayama C, Yasumura S. 2018. Association between health literacy and radiation anxiety among residents after a nuclear accident: comparison between evacuated and non-evacuated areas. Int. J. Environ. Res. Public Health 15(7): 1463. https://doi.org/10.3390/ijerph15071463.

Maeda M, Oe M. 2017. Mental health consequences and social issues after the Fukushima Disaster. Asia Pac. J. Public Health 29 (2_Suppl.): 36S-46S. https://doi.org/10.1177/ $10 \overline{10539516689695 .}$

Mashiko H, Yabe H, Maeda M, Itagaki S, Kunii Y, Shiga T, Miura I, Suzuki Y, Yasumura S, Iwasa H, Niwa SI, Ohtsuru A, Abe M. 2017. Mental health status of children after the Great East Japan Earthquake and Fukushima Daiichi Nuclear Power Plant Accident. Asia Pac. J. Public Health. 29: 131S-138S. https:// doi.org/10.1177/1010539516675702.

Mayring P. 2000. Qualitative content analysis. Forum Qual. Soc. Res. 1(2). Retrieved March 10, 2005 from http://www.qualitativeresearch.net/fqs-texte/2-00/02-00mayring-e.htm.

Murakami M, Sato A, Matsui S, Goto A, Kumagai A, Tsubokura M, Orita M, Takamura N, Kuroda Y, Ochi S. 2017. Communicating with residents about risks following the Fukushima Nuclear Accident. Asia Pac. J. Public Health. 29(2_Suppl.): 74S-89S. https://doi.org/10.1177/1010539516681841.
Nukui H, Midorikawa S, Murakami M, Maeda M, Ohtsuru A. 2018. Mental health of nurses after the Fukushima complex disaster: a narrative review. J. Radiat. Res. 59(Suppl._2): ii108-ii113. https:// doi.org/10.1093/jrr/rry023.

Oe M, Schumacher S, Schnyder U, Mueller-Pfeiffer C, Wilhelm FH, Kuelen E, Martin-Soelch C. 2016. Discriminative evaluative conditioning in the long-term after severe accidental injury. Psychiatry Res. 240: 144-150. https://doi.org/10.1016/j.psy chres.2016.04.022.

Oe M, Takahashi H, Maeda M, Harigane M, Fujii S, Miura I, Nagai M, Yabe H, Ohira T, Suzuki Y, Yasumura S, Abe M. 2017. Changes of posttraumatic stress responses in evacuated residents and their related factors. Asia Pac. J. Public Health. 29(2_Suppl.): 182S-192S. https://doi.org/10.1177/1010539516680733.

Ohno K, Kaori T. 2011. Effective education in radiation safety for nurses. Radiat. Prot. Dosimetry 147(1-2): 343-345. https://doi. org/10.1093/rpd/ncr342.

Ohto H, Yasumura S, Maeda M, Kainuma H, Fujimori K, Nollet KE. 2017. From devastation to recovery and revival in the aftermath of Fukushima's nuclear power plants accident. Asia Pac. J. Public Health 29(2_Suppl.): 10S-17S. https://doi.org/10.1177/ 1010539516675700 .

Okada T. 2014. The diversity of radiation education programs at primary schools in Fukushima Prefecture Fukushima Prefecture. Bull. Cent. Res. Dev. Educ. Fukushima Univ. 17: 59-66.

Orita M, et al. 2015. Bipolarization of risk perception about the health effects of radiation in residents after the accident at Fukushima Nuclear Power Plant. PLoS One 10(6): e0129227. https://doi.org/ 10.1371/journal.pone.0129227.

Suzuki Y, Yabe H, Yasumura S, Ohira T, Niwa SI, Ohtsuru A, Mashiko H, Maeda M, Abe M. 2015. Psychological distress and the perception of radiation risks: the Fukushima health management survey. Bull. World Health Organ. 93(9): 598-605. https:// doi.org/10.2471/BLT.14.146498.

Tsubokura M, Kitamura Y, Yoshida M. 2018. Post-Fukushima radiation education for Japanese high school students in affected areas and its positive effects on their radiation literacy. J. Radiat. Res. 59: ii65-ii74. https://doi.org/10.1093/jrr/rry010.

Tsujiuchi T, et al. 2016. High prevalence of post-traumatic stress symptoms in relation to social factors in affected population one year after the Fukushima Nuclear Disaster. PLoS One 11(3): e0151807. https://doi.org/10.1371/journal.pone.0151807.

Yamaguchi K. 2019. Diversified activity for radiation education in Fukushima Prefecture. J. Jpn. Soc. Sci. Educ. 42: 159-160.

Yasui K, Kimura Y, Kamiya K, Miyatani R, Tsuyama N, Sakai A, Yoshida K, Yamashita S, Chhem R, Abdel-Wahab M, Ohtsuru A. 2017. Academic responses to Fukushima disaster. Asia Pac. J. Public Health. 29(2_Suppl.): 99S-109S. https://doi.org/10.1177/ 1010539516685400 .

Yoshida M, Honda E. 2018. Current status and history of radiation education; considering the Fukushima Dai-ichi nuclear disaster. Ochanomizu igaku zasshi. 66(2): 227-245.

Yoshida N, Kanda J. 2012. Tracking the Fukushima radionuclides. Science 336(6085): 1115-1116. https://doi.org/10.1126/sci ence. 12194.

Cite this article as: Kuroda Y, Tsubokura M, Sasaki K, Hara T, Chiba A, Mashiko K, Schneider T. 2020. Development of radiation education in schools after the Fukushima Daiichi nuclear power plant accident-a study from the perspectives of regionality, multidisciplinarity and continuity. Radioprotection 55(4): 317-324 